\title{
Motivation and Emotions among Top Players in the Western Balkan Basketball Teams
}

\author{
Nenad Suzić ${ }^{1}$ and Slobodan Simović ${ }^{2}$ \\ ${ }^{1}$ Faculty of Philosophy, Univerzity of Banja Luka, Banja Luka, Bosnia and Herzegovina \\ ${ }^{2}$ Faculty of Physical Education and Sports, Univerzity of Banja Luka, Banja Luka, Bosnia and Herzegovina \\ nenad_szc@yahoo.com,s.simovic2011@gmail.com
}

\begin{abstract}
This study was conducted on the sample of 127 top level basketball players from 11 different teams in three countries from the Western Balkans. Two significant findings were found in this paper. The first one is consisted of six motivational variables (controlled motivation, autonomous motivation, external regulation, introjected regulation, identified regulation, and intrinsic motivation) out of which four predictor variables were singled out. The multiple regression was used to establish that the variable of identified regulation significantly predetermined the variable of handling relationships. Combined with external regulation, it led to a decrease in efficiency of cooperative and interactive performance of basketball players. The other significant finding was the fact that top basketball players from the Western Balkans differed among themselves in the level of reading and managing emotions. This finding may prove to be useful to managers and coaches as they can apply it through education and interactive workshops in order to establish positive mutual influencing among team members, i.e. to facilitate those with lower levels of managing emotions to be able to learn from the players who possess higher levels of managing emotions and reading emotions as well.
\end{abstract}

Index Terms - managing emotions, reading emotions, identified regulation, handling relationships, regulation

\section{Introduction}

Being a team sport, basketball implies that gifted and efficacious individuals attribute their abilities to a collective and perform as members of a team. In an article in The New York Times, Carl Sagan defined the modern basketball as follows: "Basketball at its best becomes a synthesis of the highest intelligence, precision, courage, boldness, audaciousness, anticipation, team work, elegance and gracefulness" [1]. The modern civilization strives to incorporate human abilities into group settings. Therefore, two components can be seen as crucial in achieving success: team building, i.e. team cooperation, and acceptance of changes [2].

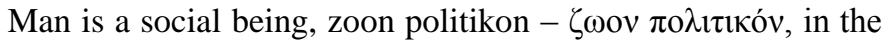
words of Aristotle, but also self-determined. That means that a person is free to define its course of actions and cooperate with others or act alone. Self-determination theory ("SDT") embodies both of these aspects [3]. In order to establish sound functioning in a social context, a man should meet the three key needs: autonomy, competence and relatedness [3, 4]. Basketball is a sport which integrates these three concepts. Research has shown that cooperation among players alleviates the stress level [5]. Another one has indicated that selfdetermination reduces athlete burnout [6].

The question now is how to recognize autonomy, competence and relatedness in basketball? Autonomy is identified as a behavior in which a person reaches a high level of independence and self-affirmation. As an autonomous individual, basketball player initiates and regulates his actions with a high level of will, enthusiasm and choice making. These are the components that are generally associated with autonomy [7]. Competence was defined by Eduard Deci [8] as a person's need to be effective in interaction with the surroundings. The simplest definition of competence describes it as ability at work [9]. For instance, for someone who cannot ride a bicycle we can't say he is not able to ride a bicycle. Such a person will be said to be competent only when he learns to ride a bicycle, of course, with significant differences in the level of proficiency in this skill. Relatedness implies the need to establish close interactions with persons in your surroundings [10]. Without this competence, not even the best of basketball players would be able to play in NBA or similar top-quality competition. The continuous satisfaction of autonomy, competence and relatedness provides a person's positive functioning, strengthens and reasserts his motivation [3]. Our research specifically deals with these needs of topquality basketball players in the Western Balkans.

How to reconcile the two opposites, i.e. someone's need to be autonomous on one side and the need to establish social relatedness on the other? For example, the best of basketball players did not become such just by regularly attending training sessions at basketball camps, but by also spending hours under hoops in their neighborhoods. While spending hours and days throwing the ball, they have been dreaming of getting a chance to present their competence before the full stands at top basketball games. So, their need to be autonomous, able to handle the ball, and score points, did not separate them from being connected with other people. However, research has shown that satisfying this need may lead people to suffer of autonomy frustration [11, 12]. This is about autonomy which separates man from the socialization, and reduces man's relatedness. If a man is to be successful in modern civilization, he should learn how to live with solitude, how not to be frustrated with the state of being alone [13]. We have to bear in mind that there is a thin red line which separates normal autonomy from an excessive one, i.e. autism or behavior leading to autonomy frustration. Basketball is a sport which relates a man's need to be autonomous and his gregarious, i.e. social motives. This distinction is to be noticed by basketball coaches in particular, because it is players who make coaches successful; players on court make decisions on particular technical and tactical elements of the game they will 
perform. They harmonize their actions with reactions of their teammates and their opponents in ever changing circumstances. Through these interactions, we get situations in which players confront their opponents $[14,15]$.

\section{A. What are the motives of top basketball players?}

Renowned coaches and world-class managers having in their careers undisputable results, agree on one thing that money does not stand as the key motive for making outstanding careers in basketball $[16,17,18,19,20]$. For example, Pedro Ferrándiz, the former Real Madrid coach, says that it takes not more than a glance at teenage basketball players to conclude that they approach their training sessions without financial rewards on their mind, but only love for basketball as a game and sport [17]. Money cannot be measure for work done, because by doing so we might conclude that housewives perform no work [21]. Duško Vujošević, a wellknown basketball coach, thinks that motivation of top-class basketball players is underlain by their attitude towards the game. He also claims that it takes no more than one player with bad attitude to destroy a game plan that has been prepared and practiced on training sessions for months. He highlights the need of players to act as team members and possess strong will to win [19]. Accordingly, the experience of famous basketball coaches suggests that motives of top-class basketball players come from complex origins.

One of motives that should never be overlooked is the feeling of flow [13]. Flow is the mental state of operation in which a person in an activity is fully immersed in a feeling of energized focus, full involvement, and in terms of basketball giving in to the game itself. Flow usually occurs when a person is faced with completion of a clear and desired goal. Every flow is accompanied with various little things and details; Csikszentmihalyi calls them microflows [13]. In basketball that means preseason preparations, discussions about played games, viewing match recordings and similar things. Once you remove microflow, the flow itself is bound to disappear. That means it is necessary to provide all preconditions for players to live their professional lives to the fullest, i.e. provide for all aspects of microflow to take place. Doing what one wants is a condition sine qua non on the path to human happiness. Our research has dealt with this matter by means of testing the autonomous and intrinsic motivation of basketball players.

On one hand we have the experience of flow that overcomes basketball players and vigorously motivates them, and on the other hand there are gregarious or social motives. ERG Theory (Existence, Relatedness, Growth) Clayton Alderfer, as one of the most famous theory of social motives, treats these motives as having two factors (bifactorial) [22]. His theory redefined the three motives into the following: existence needs, relatedness needs and growth needs. Each of these motives oscillates between two factors: a) satisfaction/progression and b) frustration/regression [22]. Existence needs include psychological and safety needs such as food, water or sex. Relatedness needs include social and external esteem: family, friends, associates, employment. Growth needs include self-esteem and self-actualization, i.e. creativity, productivity, problem solving competences [22]. Even a brief glimpse into the structure of gregarious motives shows us that top-class basketball players satisfied those needs. Also, we must bear in mind that needs tend to develop over time. Take empathic accuracy for example, i.e. the need of a basketball player to infer the thoughts and feelings of his opponents or teammates. This need should be understood as a man's ability to recognize that people have different thoughts, that situations should be viewed from different angles, one should be able to understand other people's goals which cannot always be in accord with our personal interests [23]. No matter to what extent his gregarious or social motives are satisfied, a basketball player will always strive to continue improving and developing his competences as a man and professional.

\section{B. Managing emotions}

Following top basketball games at Olympics, world championships and NBA championship, it has come to our notice that managing emotions plays a very significant role in establishing a well-trained team. Not only does it matter to train basketball players to handle their own emotions, but it also matters to have them being able to handle group or team emotions. Even the very consciousness of a particular emotion, its labeling, can calm the amygdala - a center in brain which influences emotions most intensively [23]. Emotional reactions can substantially predetermine collective efficacy [24]. How team-referent attributions impact on emotions and collective efficacy was investigated in the research of Allen, Jones, and Sheffield [25]. Their findings showed that the way 265 athletes assess their individual and group emotions and the way they perceive group success significantly predetermines both their individual and team efficacy [25]. The phenomenon of team-referent attribution is very important for success of a basketball team. It is about how basketball players assess success or failure of team, what they see as cause of that and to what extent they are ready to take responsibility for group success or group failure. The research has shown that team members tend to accept greater personal responsibility for group success than group failure [26]. Fritz Heider developed the attribution theory in 1958 [27], which was subsequently related to achievement and motivation by Bernard Weiner [28]. He found that attributions are classified along three causal dimensions: 1) locus of causality, with individuals seeing causes for something internally or externally; 2) stability, i.e. an individual tries to retain stable and consistent behavior; 3) controllability, i.e. an individual tries to observe if he/she controls his/her actions or the control is imposed by an outside source [28]. All the three dimensions impact on managing emotions. The aim of the present study was to explore how this attribution impacts on the cooperation of top basketball players in the Western Balkans. For instance, we sought for an answer whether external or identified regulation predetermines a basketball player's cooperation.

Our research has hypothesized two things. First, we would be able to find out which of motivational components, one or more, posed as key predictors of a basketball player's cooperation and readiness for team work. Second, top-class 
basketball players differed among themselves in the level of reading and managing emotions. Both these hypotheses are significant when working with individuals and teams in elite basketball competitions.

\section{Method}

\section{A. Participants and Procedure}

Altogether, 127 top-class basketball players from three countries: Bosnia and Herzegovina (24), Croatia (58) and Serbia (45), all of which were male, agreed to participate in our research. Their age was ranging from 17 to 36 , with a mean age of 23 years. They were members of the following 11 basketball teams: Sloga, Bosna, Cibona, Hemofarm, Igokea, Križevci, Partizan, Zabok, Zadar, Zrinjski and Zvezda. These teams were all members of class A national competitions. Eight of them were also competing in European level leagues, while Bosna, Cibona and Partizan were all former European club champions. Participants were asked to respond to questionnaires with items presented along a Likerit-type scale. They gave their answers anonymously, but they were asked to give the sincerest answers and thus enable researchers to use their responses as means by which to come to applicable conclusions in the realm of motivation and emotions among top-class basketball players. The subsequent inspection of the answers alongside with the check-up of contradictory questions enabled us to conclude that their answers were reliable. It has taken us some seven months to collect all questionnaires, followed by data processing through application of SPSS 13 Statistica for Windows.

\section{B. Measures}

Instruments measured two phenomena, i.e. emotional competences and motivation. For the purposes of this study, we adapted and applied three instruments: How emotionally intelligent am I [29], adapted version, ASRS -The Academic Self-Regulation Scale [30] and SCT-Inventory - Sport goals of competitors (instrument designed for this study) [9]. Each of the instruments will here be described in more details. How emotionally intelligent am I [29] is the instrument which assesses emotional competences in four subtests; respondents were giving answers on a Likerit scale ranging from $1=I$ totally disagree to $5=I$ totally agree. The first subtest measures emotional self-consciousness and has three items $(\alpha$ $=.66)$, one of which reads: I understand well what causes my emotions. The second subtest measures managing emotions and has six items $(\alpha=.84)$, one of which reads: I am able to overcome my anger. The third subtest measures reading emotions and has three items $(\alpha=.63)$, one of which reads: $I$ am able to see things from someone else's perspective. The fourth subtest measures a basketball player's competence to establish relationships with others and has five items $(\alpha=.69)$, one of which reads: I am good at solving problems between people. The second instrument is adapted ASRS -The Academic Self-Regulation Scale [30]. It has 16 items each of which possesses a respectable index of internal consistency $(\alpha$ $=.81)$. The data on the calibration of our adaptation were set against the calibration data provided by Vansteenkiste, Sierens, Soenes, Luyckx, and Lens [31], and reported in Table 1.
Cronbach's alpha coefficients are respectable and almost matching in the application of ASRS-Scale on our sample relative to alpha coefficients of Vansteenkiste, Sierens, Soenes, Luyckx, and Lens [31]. Total of sixteen questions were answered by means of Likerit-type scale with answeres ranging from $1=I$ totally agree to $5=I$ totally disagree. The first subtest measures external regulation and has four items, one of which in our adaptation reads: I train basketball because I am imposed to do so by someone else (parents, friends, coach, club management, money, etc). In this case we reversed the scale and got 1 to mean totally agree and 5 to mean totally disagree. The second subtest has four items and measures introjected regulation. One of its items reads: I train basketball because I would have a sense of guilt if I skipped training sessions or games. The third subtest is related to identified regulation and has four items, one of which reads: $I$ train basketball because it matters to me. The fourth subtest measures intrinsic motivation and has four items, one of which reads: I train basketball because I enjoy it. As we can see, these items have traits of flow experience motivation [13], e.g. enjoyment, and gregarious motives [22], training basketball in the group and for the group. The third instrument SCTInventory - Sport goals of competitors [9], was specially designed for the purpose of this study. It has twenty items in two subtests, and the internal consistency of the entire instrument, measured by Cronbach's alpha coefficient, is $\alpha$ $=.69$. The first subtest has ten items and measures player's mastery orientation $(\alpha=.63)$, with one item reading: I want to practice more as it helps to enhance my abilities. The second subtest measures performance orientation and has ten items $(\alpha$ $=.63$ ), with one item reading: For me it is important to be better than others.

\section{Results}

\section{A. Plan of Analysis}

We used multiple regression [32] analysis to prove the first hypothesis and also to prove which motivational component is the key predictor of cooperation or orientation of a player to establish relationships with other players. In order to prove the second hypothesis, we applied analysis of variance (ANOVA, ibidem) as to be able to find out variations between basketball players in terms of reading and handling emotions. In order to implement multiple regression adequately, we first set all components of emotional competences against the components of motivation (Table 1). In that way we found which correlations were deemed significant. We were interested into the matter of which motivational components predetermine cooperation of basketball players, as one of emotional competences. Out of six motivational components, the four were significantly related to handling relationships, and they were the following: autonomous motivation $(r=.40$; significant at the .01 level), external regulation ( $r=-.31$; significant at the .01 level), identified regulation ( $r=.40$; significant at the .01 level) and intrinsic motivation ( $r=.34$; significant at the .01 level). Measured according to Pearson's model, the coefficients are significant at the .01 level, but we cannot be sure whether they 
equally act as predictors of cooperation and interactivity of basketball players. Multiple regression remains the best statistical method to find out this prediction.

TABLE I Descriptive Statistics and Intercorrelation Matrix for the Dependent Variables

\begin{tabular}{|c|c|c|c|c|c|c|c|c|c|c|c|c|}
\hline Dependent measure & $M$ & $S D$ & 1 & 2 & 3 & 4 & 5 & 6 & 7 & 8 & 9 & 10 \\
\hline 1. Emotional self-awareness & 4.11 & .71 & - & $.65^{* *}$ & $.44^{* *}$ & $.38 * *$ & -.11 & $.27^{* *}$ & $-.16^{*}$ & -.05 & $.26^{* *}$ & $.24 * *$ \\
\hline 2. Managing emotions & 4.05 & .73 & & - & $.53 * *$ & $.40 * *$ & $-.16^{*}$ & $.42^{* *}$ & $-.27 * *$ & -.04 & $.37 * *$ & $.43^{* *}$ \\
\hline 3. Reading emotions & 4.15 & .62 & & & - & $.75 * *$ & -.09 & $.36^{* *}$ & $-.25^{* *}$ & .05 & $.35^{* *}$ & $.32 * *$ \\
\hline 4. Handling relationships & 4.21 & .53 & & & & - & -.13 & $.40^{* *}$ & $-.31 * *$ & .04 & $.40^{* *}$ & $.34 * *$ \\
\hline 5. Controlled motivation & 2.05 & .87 & & & & & - & .09 & $.79 * *$ & $.90^{* *}$ & .12 & .04 \\
\hline 6. Autonomous motivation & 4.48 & .64 & & & & & & - & $-.20^{*}$ & $.26^{* *}$ & $.94 * *$ & $.93^{* *}$ \\
\hline 7. External regulation & 1.76 & .85 & & & & & & & - & $.44^{* *}$ & $-.15^{*}$ & $-.23 * *$ \\
\hline 8. Introjected regulation & 2.35 & 1.18 & & & & & & & & - & $.29^{* *}$ & $.23 * *$ \\
\hline 9. Identified regulation & 4.44 & .70 & & & & & & & & & - & $.75^{* *}$ \\
\hline 10. Intrinsic motivation & 4.53 & .65 & & & & & & & & & & - \\
\hline
\end{tabular}

Note: ** Correlation is significant at the .01 level (1-tailed); * Correlation is significant at the .05 level (1-tailed).

The first four components in Table 1 represent emotional intelligence, whereas the remaining six relate to motivation. Correlations show that out of six motivational components the following four can be taken as predictors: autonomous motivation, external regulation, identified regulation and intrinsic motivation. These four components have been singled out because of their significant correlation, as recommended by Bryman and Cramer [32], and with variable of our special interest.

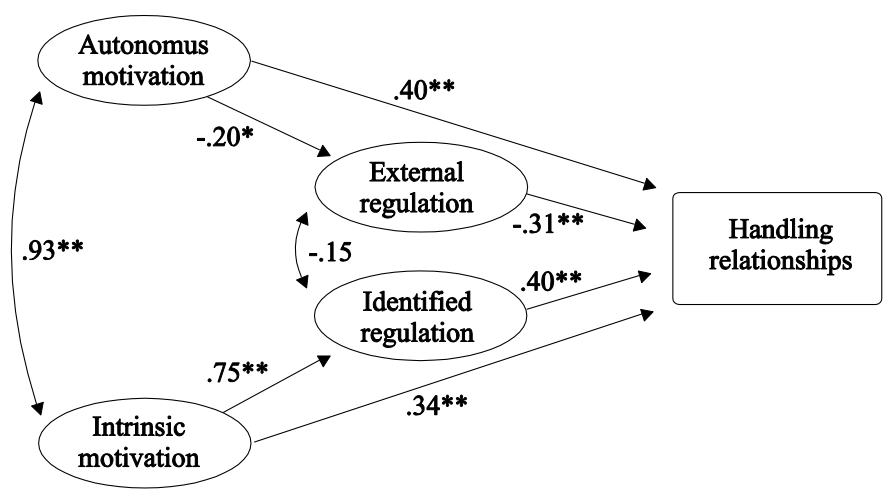

Fig. 1 Which motives predetermine readiness of basketball players to establish interpersonal relationships (Test model)

That is the variable which reflects readiness of basketball players to establish interpersonal relationships. The reason why we brought this into focus of our interest is the fact that basketball is a team sport. To test this predilection, we designed a regression model (Figure 1), in which we tested in what manner correlations would be changed when subject to multiple regression, i.e. when we converted them into betaquotients. With multiple regression completed, we ended up with two models. In the first model the salient variable was identified regulation as the key predictor in readiness of basketball players to establish relationships with others (Model 1, $\beta=.40$ significant at the .01 level, which accounted for $16 \%$ of variance, $R^{2}=.16$ ). Let us now talk about the variable of identified regulation. Here we asked respondents how important the training sessions were for them as a goal of their action and if that mattered to them, i.e. that was how we adapted instruments designed by Ryan and Connell [30]. Accordingly, here we found out that importance of basketball in lives of top-class basketball players had a key role in their readiness and determination to establish relationships with teammates and other people. This finding is in accord with research which confirmed that team identification is positively related to social affiliation and the feeling of well-being [33].

The second model (Figure 2) reports that level of identified regulation decreases $(\beta=.37$ significant at the .01 level) in combination with external regulation $(\beta=-.25$ significant at the .01 level). In other words, if coaches make pressure on players, it results in a decreased identified regulation (from $\beta=.40-$ Model 1 to $\beta=.37$ - Model 2; Figure 2). This finding is in line with the results reached by Thatcher, Kuroda, Thatcher, and Legrand [34], whereby the authors have proved that non-dominant behavior of leaders reinforces the focus of attention and valuation of training sessions. The finding in our research demonstrates that the higher the pressure the lower the identified regulation. This piece of information could be useful for basketball coaches. Moreover, it implies that exercising pressure on individual basketball players or teams, leads to reduced identified regulation which is considered to be the basic source of motivation. 
Model 1 ( $\beta$ coefficients in multiple regression)

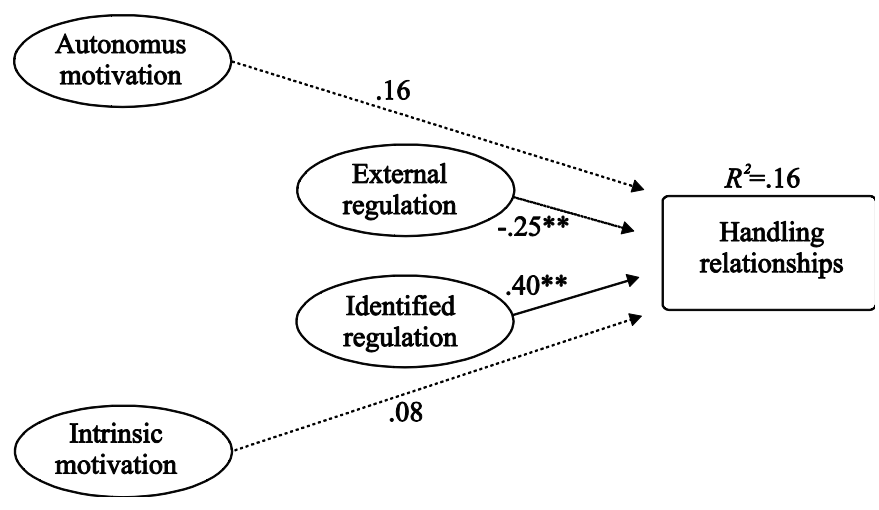

Model 2 ( $\beta$ coefficients in multiple regression)

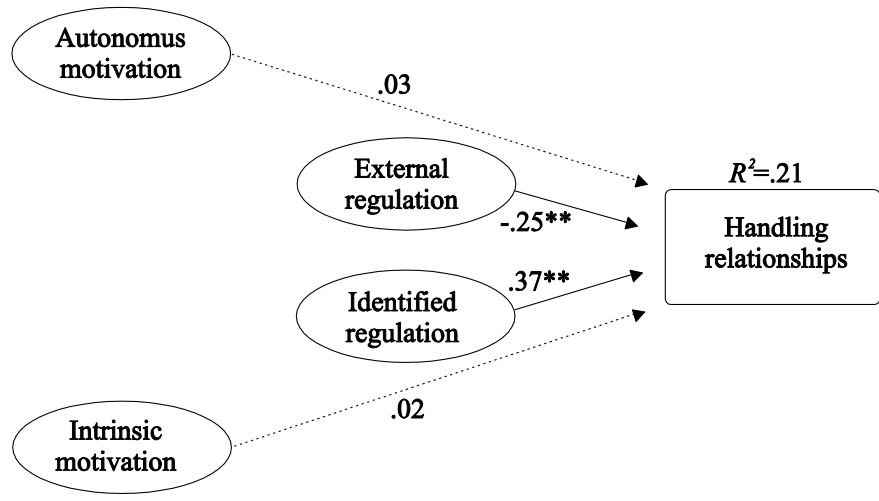

Note: Solid lines mark beta coefficients, whereas dotted lines have beta coefficients removed

Fig. 2 Key components of motivation as predictors of readiness of basketball players to establish interpersonal relationships
One of the most accepted definitions of emotional intelligence is the one proposed by Peter Salovey and John Mayer [35], which is said to include the ability of perception and expression of emotions, and ability to understand and regulate emotions. Later, Daniel Golemann [2] suggested four key components of emotional intelligence: 1) emotional selfawareness, 2) managing emotions, 3) reading emotions, and 4) handling relationships. In this definition the stress is more on emotional competences than on emotional intelligence. John Santrock used these components to design the instrument titled How Emotionally Intelligent Am I [29]. We used this instrument to test basketball players in our sample. In basketball, it is very important to manage emotions, read them on other players, be they from within a team or from the opposing team. It is also important to channel and organize your own as well as group emotions. Emotional reactions may play a predisposing role in individual and collective (team) efficacy [24]. Such efficacy increases motivation over time [36]. In our study we found that basketball players differ in two components of emotional competences: emotional selfawareness $\left(F_{(4)}=8.05\right.$; significant at the .001 level, Table 2) and managing emotions $\left(F_{(4)}=3.53\right.$; significant at the .032 level; Table 2). Since basketball players significantly differ among themselves in terms of emotional self-awareness and managing emotions, this finding might be relevant to basketball managers and coaches as to achieve better quality of the mentioned competences through education and group interaction. For example, players with higher levels of managing emotion competence could share their experience with their teammates, all in order to use their emotional strengths as both individuals and group members. This may eventually lead to better group cohesion and better results.

TABLE II Years of experience and emotional competences ratio (ANOVA)

\begin{tabular}{|c|c|c|c|c|c|c|c|}
\hline \multirow{2}{*}{ Variable } & \multicolumn{7}{|c|}{ Differences between groups of basketball players arranged according to years of experience } \\
\hline & $N$ & $M$ & $S D$ & Sum of squares & Average sum of squares & $F_{(4)}$ & $p$ \\
\hline Emotional self-awareness & 127 & 4.11 & .71 & 7.20 & 3.60 & 8.05 & .001 \\
\hline Managing emotions & 127 & 4.05 & .73 & 3.63 & 1.82 & 3.53 & .032 \\
\hline Reading emotions & 127 & 4.15 & .62 & 1.78 & .89 & 2.38 & .097 \\
\hline Establishing relationships & 127 & 4.21 & .55 & 1.10 & .55 & 1.86 & .160 \\
\hline EC: Emotional competences & 127 & 4.13 & .53 & 2.44 & 1.22 & 4.64 & .011 \\
\hline
\end{tabular}

By examining the arithmetic means in Table 2, we observe that establishing relationships $(M=4.21)$ is the most salient component of emotional competences among basketball players. It is not surprising therefore that this component of emotional competences is crucial in predetermining establishing relationships, i.e. cooperation of basketball players among themselves (Figure 2, Model 1). This finding is in accord with research results which support the notion that social support of athletes strengthens their confidence, and their emotional self-awareness alleviates stress [37]. Table 2 reports high scores in emotional competences of basketball players. All competences were assessed by means of Likerit-type scale ranging from one to five. They were conducted based on self-reporting and selfevaluation of basketball players - i.e. they were grouped around it is true for me category, which meant that their mean is $M=4.13$ (Table 2). We found no need to question their selfevaluation responses such as I can handle well my own anger. It is a well-known fact that people rarely give biased answers on questions of such nature. To conclude, emotional competences of basketball players in the Western Balkans are at a very high level. This is not surprising as our respondents were mainly international star trackers. Daniel Goleman contends that emotional intelligence is twice as much 
important as cognitive intelligence if one is to accomplish a top-class success [2]. Some analyses pertaining success in NBA highlight the following three components: communicative competence, initiative, and interpersonal competences [38]. Our research (Table 2) has readily shown that emotions, reading of emotions, managing emotions, and establishment of social relationships are highly developed among basketball players in the Western Balkans. This is in accord with research proving that emotional self-control and relaxation contribute to an athlete's efficacy [39]. Generally, while proving the second hypothesis we have clearly come to a conclusion that some basketball players have higher level of emotional self-awareness whereas the others are better at managing (controlling) their emotions. For basketball coaches and managers this finding may serve as clear guidance towards experience sharing actions. It also urges all of them to influence one another, so those with higher level of reading emotions could impact those with lower levels. The same holds true for players with higher levels of managing emotions.

\section{General Discussion}

We have come to two significant findings in this study. First, a basketball player's readiness to cooperate with others is mostly predetermined by identified regulation, which is susceptible to decrease if external control is exerted on players. Second, basketball players differ among themselves in the levels of managing and reading emotions. These findings are important for both basketball coaches and players. In terms of group cooperation, the first finding indicates what steps are to be taken if a group cohesion and increased motivation are to be achieved. In terms of having an influence on players with lower levels of managing and reading emotions, the second finding calls for interactive workshops that may be beneficial for all team members.

Identified regulation, as one of six motivational variables, is found to be predetermining in terms of how basketball players will handle interpersonal relationships. This predilection has been reached at through two stages. First, the six motivational variables were set against the four emotional competences. Second, the four variables that significantly correlate with handling relationships multiple regression were tested as predictors. Support reinforces self-confidence [37]; we found out which motivational variable is crucial in encouraging support among top-level basketball players. When we concluded that external regulation, alongside with identified regulation, negatively impacted handling relationships and reduced the effect of identified regulation (Model 2), we confirmed the study that domination is not good for top sport [34]. It should be emphasized that this finding did not account for all motivational predictors for cooperation and interactive collaboration among basketball players. We still managed to point out what is essential within the group of motivational variables ranging from external control to internal motivation. The instruments used for measuring motivation partly accounted for the experience of flow. Further research is necessary if a more detailed influence of flow on establishing relationships among players could be accounted for. The importance of setting goals and achievements and their relation to handling relationships among basketball players should also be in focus of further research.

Our study also found that top basketball players differ among themselves in competences related to reading emotions and managing (controlling) emotions. Even reading emotions itself comes as a presumption for managing emotions [23]. In our research we found that basketball players have high level of self-assessment in terms of reading emotions $(M=4.15)$. If a person sees locus of control as external, then he/she will react negatively [28] and try to control a situation by himself/herself. Managing emotions among top-class basketball players is very high. Our sample reported the mean value for managing emotions as $M=4.05$, which is considered to be high level on our assessment scale. Once the high level of managing emotions is provided, concentration and efficacy of athletes are increased accordingly [39]. Our study also gives reasons for optimism coming from our finding that topclass basketball players in the Western Balkans possess substantially high level of managing emotions. However, an unexpected finding is that there is a statistically significant difference among basketball players in terms of reading and managing emotions $(F=3.53$ significant at the .05 level $)$. We could not clarify whether it was due to generation gap, or by what criteria this difference appeared. We have simply come to a conclusion that a group of basketball players have a higher level of reading emotions, whereas the other group has a higher level of emotional self-control. This particular finding may be useful when it comes to harmonizing basketball players' advantages, but it also leaves space for new research in the matter of the origin of those differences and their possible impact on the game itself.

\section{References}

[1] S. Trninic, Analysis and teaching of basketball games, Pula: CRO VITIKA d.o.o., 2005, p. 22.

[2] D. Goleman, Working with emotional intelligence, New York: Bantam Book, 1998, p. 34.

[3] R.M. Ryan and E.L. Deci, "Self-determination theory and the facilitation of intrinsic motivation, social development, and well-being", American Psychologis, no. 55, pp. 68-78, 2000.

[4] J. Reeve, E.L. Deci, and R.M. Ryan, "Self-determination theory: A dialectical framework for understanding the sociocultural influences on student motivation", in Research on sociocultural influences on motivation and learning: Big theories revisited, vol. IV, D. McInerney and S. Van Etten, Eds., Greenwich: Information Age, 2004, pp. 31-59.

[5] M. Kaiseler, R.C.J. Polman, and A.R. Nicholls, "Effects of the Big Five personality dimensions on appraisal coping, and coping effectiveness in sport", European Journal of Sport Science, vol. 12, no. 1, pp. 62-72, 2012.

[6] P. Lemyre, G.C. Roberts, and j. Stray-Gundersen, "Motivation, overtraining, and burnout: Can self-determinated motivation predict overtraining and burnout in elite athletes?", European Journal of Sport Scienc, vol. 7, no. 2, pp. 115-126, 2007.

[7] J. Reeve, G. Nix, and D. Hamm, "Testing models of the expirience of self-determination in intrinsic motivation and the coundrum of choice", Journal of Educational Psychology, no. 95, pp. 375-392, 2003.

[8] E.L. Deci, Intrinsic motivation, New York: Plenum, 1975.

[9] N. Suzic, "The eight key competences for lifelong learning", Vaspitanje i obrazovanje - časopis za pedagošku teoriju i prkasu, no. 3, pp. 13-27, 2010. 
[10] R.F. Baumeister, and M.R. Leary, "The need to belong: Desire for interpersonal attachment as a fundamental human motivation", Psychological Bulletin, no. 117, pp. 497-529, 1995.

[11] E.L. Deci, R.M. Ryan, M. Gagné, D.R. Leone, J. Usunov, and B.P. Kornazheva, "Need satisfaction, motivation, and well-being in the work organizations of a former Eastern Bloc country: A cross-cultural study of self-determination", Personality and Social Psychology Bulletin, no. 27, pp. 930-942, 2001.

[12] M. Vansteenkiste, M. Zhou, W. Lens, W., and B. Soenens, "Experiences of autonomy and control among Chinese learners: Vitalizing or immobilizing?", Journal of Educational Psychology, no. 97, pp. 468483, 2005.

[13] M. Csikszentmihalyi, Finding flow - The psychology of engagement with everyday life, New York: Basic Books, 1997.

[14] K. Davids, C. Handford, and M. Williams, "The natural physical alternative to cognitive theories of motor behavior: An invitation for interdisciplinary research in sports sciences?", Jouranl of sport sciences, vol. 12, no. 6, pp. 495-528, 1994.

[15] J.F. Gréhaigne, and P. Godbout, "Tactical knowledge in team sports from a constructivist and cognitivist perspective", Quest, no. 47, pp. 490-505, 1995.

[16] J.M. Buceta, "The motivation of elite players", FIBA Asist Magazine, no. 6, pp. 35-36, 2004.

[17] P. Ferrándiz, "Educational professionalism", FIBA Asist Magazine, no. 17, pp. 33-34, 2005.

[18] L. Janssen, "Six ways to win with better team captains", FIBA Asist Magazine, no. 18, pp. 33-34, 2006.

[19] D. Vujosevic, "Building a championship team". FIBA Asist Magazine, no. 2 , p. $36,2003$.

[20] R. Zeravica, "Psychological preparation", FIBA Asist Magazine, no. 16, pp. 33-34, 2005.

[21] J. Kondo, Motivation, creativity and quality control: a Japanese perspective, Beograd, SRB: Evropski centar za mir i razvoj, 1997.

[22] C.P. Alderfer, "An empirical test of a new theory of human need", Behavior \& Human Performance, vol. 4, no. 2, pp. 142-175, 1969.

[23] D. Goleman, Social intelligence, the new science of human relationships, New York: Bantam Book, 2006, p. 136.

[24] S.G. Barsade, "The ripple effect: Emotional contagion and its influence on group behavior", Administrative Science Quarterly, no. 47, pp. 644$675,2002$.

[25] M.S. Allen, M.V. Jones, and D. Sheffield, "Attribution, emotion, and collective efficacy in sports teams", Group Dynamics: Theory, Research, and Practice, vol. 13, no. 3, pp. 205-217, 2009.
[26] D.K. Sherman and H.S. Kim, "Is there an 'I' in 'team'? The role of the self in group-serving judgments", Journal of Personality and Social Psychology, no. 88, pp. 108-120, 2005.

[27] F. Heider, The psychology of interpersonal relations, New York: Wiley, 1958.

[28] B. Weiner, "An attributional theory of achievement motivation and emotion", Psychological Review, vol. 92, no. 4, pp. 548-573, 1985.

[29] J.W. Santrock, Human adjustment, New York: Mc Graw Hill, 2006, p. 159.

[30] R.M. Ryan and J.P. Connell, "Perceived locus of causality and internalization: Examining reasons for acting in two domains", Journal of Personality and Social Psychology, no. 57, pp. 749-761, 1989.

[31] M. Vansteenkiste, E. Sierens, B. Soenes, K. Luyckx, and W. Lens, "Motivation profiles from a self-determination perspective: The quality of motivation matters", Journal of Educational Psychology, vol. 101, no. 3, pp. 671-688, 2009.

[32] A. Bryman, A. and D. Cramer, Quantitative data analysis with SPSS release 10 for Windows: A guide for social scientists. New York: Routledge, 2001.

[33] D.L. Wann, P.J. Waddill, J. Polk, and S. Weaver, "The team identification-Social psychological health model: Sport fans gaining connections to others via sport team identification", Group dynamics: Theory, Research, and Practice, vol. 15, no. 1, pp. 75-89, 2011.

[34] J. Thatcher, Y. Kuroda, R Thatcher, and F. Legrand, "Perceptual and cognitive responses during exercise: Relationships with metamotivational state and dominance", European Journal of Sport Science, vol. 10, no. 3, pp. 199-207, 2010.

[35] P. Salovey and J.D. Mayer, "Emotional intelligence", Imagination, Cognition, and Personality, no. 9, pp. 185-211, 1990.

[36] A, Bandura, Self-Efficacy: The exercise of control, New York: Freeman, 1997.

[37] P. Freeman, and T. Rees, "Perceived social support from team-mates: Direct and stress-buffering effects on self-confidence", European Journal of Sport Science, vol. 10, no. 10, pp. 59-67, 2010.

[38] K.O. Dowd and J. Liedtka, "What corporations seek in MBA hires", The Magazine of the Graduate management Admission Council, no. 10, pp. 34-39, 2004.

[39] L. Crust and K. Azadi, "Mental thoughness and athletes' use of osychological strategi", European Journal of Sport Science, vol. 10, no. 1. pp. 43-51, 2010. 